\title{
Benchmarks
}

8.Wyllie, A.H, J.F.R. Kerr and A.R. Currie. 1980. Cell death: the significance of apoptosis. Int. Rev. Cytol. 68:251-306.

This work was supported by the Atomic Energy Control Board of Canada, Project No. 7.2233.1. Address correspondence to Narine Kizilian, Health Canada, Radiation Protection Bureau, 775 Brookfield Rd, Postal Locator 6303B, Ottawa, ON, K1A 1C1, Canada. Internet: narine_kizilian@ hc-sc.gc.ca

Received 7 May 1999; accepted 20 August 1999.

\author{
N. Kizilian, R.C. Wilkins, P. \\ Reinhardt, C. Ferrarotto, \\ J.R.N. McLean and \\ J.P. McNamee \\ Health Canada \\ Ottawa, ON, Canada
}

\section{Rapid Screening of Elution Conditions Prior to Immunopurification of Proteins}

BioTechniques 27:930-934(November 1999)

Attempts are frequently made to purify the desired proteins to the state of homogeneity by using an immunoaffinity column chromatography. The readymade immunoaffinity supports that are used in the process offer rapid and high-efficiency coupling of ligands, and are commercially available (1). Most of the laboratory work is spent testing the conditions that will ensure a highly efficient elution of active proteins. Since the availability of a ligand or an antibody is often limited, it is important to develop a procedure that will consume minimum amounts of those reagents and allow for a multiple use of the immunoaffinity column. A typical screening procedure involves a series of pilot purifications, which use different types of increasingly strong elution agents.

We are proposing an alternative, a simple, fast method to determine the efficiency of elution of an antigen from the immunoaffinity column before the actual purification run. To elute active proteins with high recovery, it is essential to compromise between the harsh or even denaturing conditions that usually yield inactive products and the mild ones that preserve both the antibody and the ligand in an active state, but are characterized as low-efficient. We have tested several elution conditions, listed below, and a more complete list of suggested elution reagents can be found elsewhere (1).

The enzyme selected for the exemplary immunopurification described here was restriction endonuclease $C$ viJI, derived from an IL-3A phycodnavirus-infected Chlorella and known to be sensitive to inactivation (3). We used the following steps in the immunoscreening procedure.

Step 1. The monoclonal antibody column was prepared with the use of activated resin Affi-Gel ${ }^{\circledR} 10$ Immunoaffinity Support (Bio-Rad, Hercules, CA, USA). The support was mixed with the 3CD2 anti-CviJI monoclonal antibodies and processed as instructed by the manufacturer.

Step 2. Eluting solutions, which might successfully work, were prepared: (a) TBST [50 mM Tris- $\mathrm{HCl} \mathrm{pH}$ $8.0,0.5 \mathrm{M} \mathrm{NaCl}, 5 \mathrm{mM}$ sodium azide, $0.1 \%$ Tween $\left.{ }^{\circledR} 20(20 \mathrm{~mL})\right]$; (b) $5 \mathrm{M}$ $\mathrm{LiCl}$ in $10 \mathrm{mM}$ HEPES, pH 7.0; (c) 1 $\mathrm{M}$ guanidine $\mathrm{HCl}$; (d) $2 \mathrm{M}$ guanidine $\mathrm{HCl}$; (e) $1 \mathrm{M}$ urea; (f) $2 \mathrm{M}$ urea, (g) $2 \mathrm{M}$ $\mathrm{MgCl}_{2}, 20$ mM HEPES, pH 6.0; (h) 3.5 $\mathrm{M} \mathrm{MgCl}_{2}, 20 \mathrm{mM}$ HEPES, pH 6.0; (i) 100 mM glycine, pH 2.5; (j) 50\% ethylene glycol, $10 \%$ glycerol, $3 \mathrm{mM}$ Tris$\mathrm{HCl}, \mathrm{pH} 8.0$; and (k) deionized water.

Step 3. Rectangular pieces of nitrocellulose membrane (Whatman International, Maidstone, Kent, England, UK) were cut, approximately $5.5 \mathrm{~cm}$ long and $0.5 \mathrm{~cm}$ wide $\left(0.25 \mathrm{~cm}^{2}\right.$ per one eluting agent). One extra square was added as a control of detection reaction. At this stage, it was possible to choose the composition of incubation buffer and temperature, which would preserve the native state of antigens. The pieces of membrane were incubated for $30 \mathrm{~min}$ at $4^{\circ} \mathrm{C}$ with the $C$ viJI (3) antigen solution [recombinant $C$ viJI endonuclease at a concentration of $2.3 \mu \mathrm{g} / \mathrm{mL}$ in $10 \mathrm{~mL}$ of buffer: $20 \mathrm{mM}$ Tris-acetate, $\mathrm{pH}$ 7.2, at $25^{\circ} \mathrm{C}, 0.5 \mathrm{mM}$ EDTA, $0.1 \mathrm{mM}$ dithiothreitol (DTT), $50 \mathrm{mM} \mathrm{K} \mathrm{OAC,} 5 \mathrm{mM}$ $\mathrm{Mg}$ OAC, $10 \%$ glycerol]. In general, once an antigen is immobilized, its thermal stability increases. Thus, membranes were treated at room temperature (RT). The benefit of higher

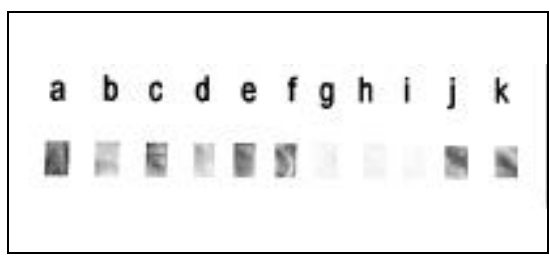

Figure 1. Testing 3CD2 antibody elution conditions from $C$ viJI antigen immobilized on a nitrocellulose membrane. Each antigen-treated nitrocellulose square was incubated with the monoclonal antibody, washed in appropriate elution agent and subjected to color detection using anti-mouse IgG-alkaline phosphatase conjugate and NBT/BCIP. Eluting solutions tested included: (a) TBST (control); (b) $5 \mathrm{M} \mathrm{LiCl}$ in $10 \mathrm{mM} \mathrm{HEP-}$ $\mathrm{ES} \mathrm{pH} \mathrm{7.0;} \mathrm{(c)} 1 \mathrm{M}$ guanidine $\mathrm{HCl}$; (d) $2 \mathrm{M}$ guanidine $\mathrm{HCl}$; (e) $1 \mathrm{M}$ urea; (f) $2 \mathrm{M}$ urea; (g) $2 \mathrm{M}$ $\mathrm{MgCl}_{2}, 20 \mathrm{mM}$ HEPES, pH 6.0; (h) $3.5 \mathrm{M} \mathrm{MgCl}_{2}$, $20 \mathrm{mM}$ HEPES, pH 6.0 (i) $100 \mathrm{mM}$ glycine, $\mathrm{pH}$ 2.5 ; (j) $50 \%$ ethylene glycol, $10 \%$ glycerol, $3 \mathrm{mM}$ Tris-HCl, pH 8.0; (k) deionized water. 


\section{Benchmarks}

temperature incubation is more efficient antibody binding and washing steps.

Step 4. The membranes were blocked with TBST buffer supplemented with $0.5 \%$ casein for $30 \mathrm{~min}$.

Step 5. Then, the membranes were incubated overnight with 3CD2 anti$C$ viJI antibodies (1:10000 dilution of $3 \mathrm{CD} 2$ cell culture supernatant in $10 \mathrm{~mL}$ of TBST buffer) and washed $3 \times$ for 15 min with TBST buffer at RT.

Step 6. The membranes were cut into 11 squares that were each numbered and incubated, with one elution agent solution $(5 \mathrm{~mL})$ for $30 \mathrm{~min}$ at $4^{\circ} \mathrm{C}$. During the reaction, one control square was left in TBST solution. The low temperature was used to mimic conditions during the column immunoaffinity purification.

Step 7. Pooled together, the nitrocellulose rectangles were washed with TBST ( $3 \times$ in, $20 \mathrm{~mL}$ for $15 \mathrm{~min}$ at RT).

Step 8. The pieces were incubated with an appropriate secondary antibody, which, in our case, was antimouse IgG-alkaline phosphatase conjugate and nitroblve tetra zolium (NBT)/5-bromo-4-chloro-3 indolyl phosphate (BCIP) color reagents (Sigma, St. Louis, MO, USA) for $1 \mathrm{~h}$ at RT.

Step 9. After washing away the excess antibodies with TBST buffer $(3 \times$ in $20 \mathrm{~mL}$ for $15 \mathrm{~min}$ ), a standard colordeveloping protocol was used (2). A slow rocking was applied during all the described procedures.

Step 10. Lined up together, the dry membrane pieces were analyzed, and their color shade compared. The control square (the one incubated with TBST only) served as a negative reference. The more effective the antigenantibody complex breaking agent was, the lighter the shades of color observed. In the experiment described above, we obtained a range of shades corresponding to the strength of the elution agents used (Figure 1).

Step 11. Water-washed and air-dried squares can be conveniently stored for at least a year without loss of color intensity, if they are protected from light.

Figure 1 presents the results from the procedure. Our visual estimation of any decreased color intensity of the nitrocellulose squares allowed us to determine the increasing elution efficiency in the following order: (g) most of the antibody eluted; (h) and (i) essentially complete elution and somewhat stronger in the case of (i). Thus, the experiment allowed us to select the appropriate conditions and to proceed with purification runs using either $100 \mathrm{mM}$ glycine, $\mathrm{pH}$
2.5 or $3.5 \mathrm{M} \mathrm{MgCl}_{2}$ as efficient elution agents. We have selected solution (i) for exemplary purification because slightly better elution was achieved and also because of a known phenomenon, in which buffers containing highly concentrated $\mathrm{MgCl}_{2}$ with $\mathrm{pH}$ near neutral $(\mathrm{g}, \mathrm{h})$ form occasional precipitates (due to hydrolysis) that clog a column. The $C$ viJI restriction endonuclease was applied to a 3CD2-immunoaffinity column that was subsequently washed with buffers of increasing elution stringency. The active $C$ viJI enzyme was recovered with eluent (i) with a yield of approximately $90 \%$ (Figure 2).

The negative approach used in our procedure-binding of an antigen rather than an antibody to the membrane-has the advantage of having a universal colorimetric assay for the presence or absence of an antibody, rather than calibrating a specific assay every time for a protein of interest. Because eluting agents used in immunopurification usually have highly concentrated salts, chaotrops, solvents or $\mathrm{pH}$ far from physiological, they are strong inhibitors of enzymatic assays. Therefore, it would be difficult to rapidly and precisely determine on a microscale whether the complex has been dissociated. Antibody detection, along with a simple membrane assay, should be universally applicable to essentially all antigen/antibody pairs, since binding to nitrocellulose is a common feature of proteins, and different antibodies can be detected with the same test.

\section{REFERENCES}

1.Hardow, E. and D. Lane. 1988. Antibodies: A Laboratory Manual. CSH Laboratory Press, Cold Spring Harbor, NY.

2.Sambrook, J., E.F. Fritsch and T. Maniatis. 1989. Molecular Cloning: A Laboratory Manual, 2nd ed. CSH Laboratory Press, Cold Spring Harbor, NY

3.Swaminathan, N., D. Mead, K. McMaster, D. George, J. Van Etten and P.M Skowron. 1996. Molecular cloning of the three base restriction endonuclease R.CviJI from eukaryotic Chlorella virus IL-3A. Nucleic Acids Res. 24:2463-2469.

This work was supported by funds from Molecular Biology Resources (Milwaukee, WI, USA) made available to Dr. Piotr M. Skowron. Address corespondence to $\mathrm{Dr}$. formed at $4^{\circ} \mathrm{C}$ to avoid thermal denaturation of $C$ viJI restriction endonuclease. The Affi-Gel 10-3CD2 IgG column was equilibrated with the Loading buffer (0.05 M HEPES, pH 7.5, $10 \%$ glycerol, $0.2 \mathrm{M} \mathrm{NaCl})$ The recombinant $C$ viJI solution, pretreated with phosphocellulose P11 (3), was applied to the column and washed with the series of buffers: $(i)$ Loading buffer; (ii) wash 1: $0.05 \mathrm{M}$ HEPES, pH 7.5, $10 \%$ glycerol, $0.4 \mathrm{M} \mathrm{NaCl}$; (iii) wash 2: $0.05 \mathrm{M}$ HEPES, pH 7.5, $10 \%$ glycerol, $0.6 \mathrm{M} \mathrm{NaCl}$; (iv) wash $3: 100 \mathrm{mM}$ glycine $\mathrm{pH}$ 5.0, $10 \%$ glycerol; $(v)$ wash 4: $100 \mathrm{mM}$ glycine, $\mathrm{pH} 4.0,10 \%$ glycerol and $(v i)$ the enzyme was recovered with Elution buffer: $100 \mathrm{mM}$ glycine, $\mathrm{pH} 2.5,10 \%$ glycerol into tubes containing $2 \mathrm{M}$ unbuffered Tris-base ( $\mathrm{pH} 11.0$ ) at 8/1 vol ratio to rapidly neutralize acidic glycine solution. Lane M, Perfect 1 kb DNA ladder (CHIMERx, Madison, WI, USA); lane 1, untreated pBR322 DNA; lanes 2-13, pBR322 DNA digested with: lane 2, CviJI (control); lane 3, flow-through affinity column; lane 4, wash with loading buffer; lane 5, wash 1; lane 6, wash 2; lane 7, wash 3; lane 8, wash 4; lanes 9-13, Elution buffer. 


\section{Benchmarks}

Piotr M. Skowron, EURx Ltd., ul. Jaskowa Dolina 29, 80-286 Gdansk, Poland. Internet: piotrs@gdansk.sprint.pl

Received 9 February 1999; accepted 19 July 1999.

\author{
Sylwia M. Rutkowska ${ }^{1}$ \\ and Piotr M. Skowron" ${ }^{1,2}$ \\ ${ }^{1}$ EURx, Ltd. \\ ${ }^{2}$ Technical University \\ of Gdansk \\ Gdansk, Poland
}

\section{In Vivo Measurement of Biodistribution Kinetics of Radiolabeled Compounds in Laboratory Animals}

BioTechniques 27:934-938 (November 1999)

In pharmacokinetic studies, both the biodistribution and the time course of the distribution are of interest. There are two ways of obtaining kinetic data: (i) laboratory animals are injected with the radiolabeled reagent and sacrificed after certain time points; the radioactivity in each organ is then measured separately. This method requires a number of animals for every single time point; (ii) gamma-camera images are obtained to follow the kinetics in individual mice in vivo, a method that drastically reduces the number of animals needed, as well as the amount of radioactivity used. However, the second way requires expensive radiological equipment, which is not accessible to all laboratory scientists.

Here, we describe a simple and inexpensive method to obtain in vivo kinetic data using equipment that is present in every laboratory. Measurements of gamma and X-rays were taken with a modified radiation monitor. The modification consists of narrowing down the open-window area of the probe to a small slit or dot (see Figure 1). This step allows one to measure radiation emitted from various body regions in animals as small as mice. Because with these measurements the localization is not as exact as with the conventional method of counting separate organs, the proposed method was used in addition, i.e., organs were counted in a scintillation counter at the end of the experiment. In this way, kinetic data was obtained by monitor measurements and exact location was determined by counting separate organs.

A $\mathrm{p} / \mathrm{m}$ scintillation probe of a Minimonitor series 900 (Mini-Instruments LTD, Essex, England, UK), ranging from $15-500 \mathrm{keV}$, and built for detection of $125 \mathrm{I}$, was used. The monitor was modified as follows: a lead shield was built from lead sheets, to slide over the probe and leave an open area of variable size and shape. First, rectangular pieces of 1.5-2 mm-thick lead sheets were cut to a size of $10 \mathrm{~cm} \times 16 \mathrm{~cm}$ and rolled to form a cylinder that would fit snugly over the probe (with a $1 \mathrm{~cm}$ overlap). The cylinder was soldered together with lead solder. The two round end plates were made from the same lead foil, but in two layers $(3-4 \mathrm{~mm}$ thick). A slit of $1.5 \times 15 \mathrm{~mm}$ was cut out in the middle of each plate. One end plate was soldered to the end of the lead cylinder, leaving an open area of $1.5 \times$ $15 \mathrm{~mm}=23 \mathrm{~mm}^{2}$ in the window of the probe. The second round plate was taped over the first one at a variable angle that further regulated the open area. Taping the plate so that the two slits were perpendicular to each other left a square of $1.5 \times 1.5 \mathrm{~mm}$ or $2.3 \mathrm{~mm}^{2}$. Taping the plate at an angle other than $90^{\circ}$ left a bigger open area that was between 2.3 and $23 \mathrm{~mm}^{2}$. This allowed us to adjust the sensitivity in separate animal experiments in which we used different total injected doses. The costs for materials were approximately \$20.

Using the modified probe, we could distinguish eight different body regions in mice. We used ${ }^{125} \mathrm{I}$-labeled reagents and measured their biodistribution in nu/nu mice. A total dose of 40-100 million counts per minute was injected intravenously. Free iodine was determined to be less than $5 \%$ in most cases. We obtained kinetic data of 15 different 125I-labeled compounds in a total of 128 mice and compared the data to numbers obtained using the conventional method of counting separate organs. Blood samples were also taken from the tail vein at time points of monitor measurements for blood clearance determination. This was of importance to appreciate the level of background counts due to radioactivity in the blood. It was also important to always keep the same angle and distance for each measurement, so only one person measured one set of data.

Data sets obtained from the two different methods of measurements were consistent with each other. Figure 2 presents an example in which the biodistribution of ${ }^{125}$ I-labeled Paclitaxel (Molecular Probes, Eugene, OR, USA) was investigated in nu/nu mice. Figure 2A shows measurements at five different time points with the modified minimonitor. Figure 2B illustrates the data from separately counted organs (conventional method) after sacrifice of the respective mice. In Figure 2A, counts per minute measured with the

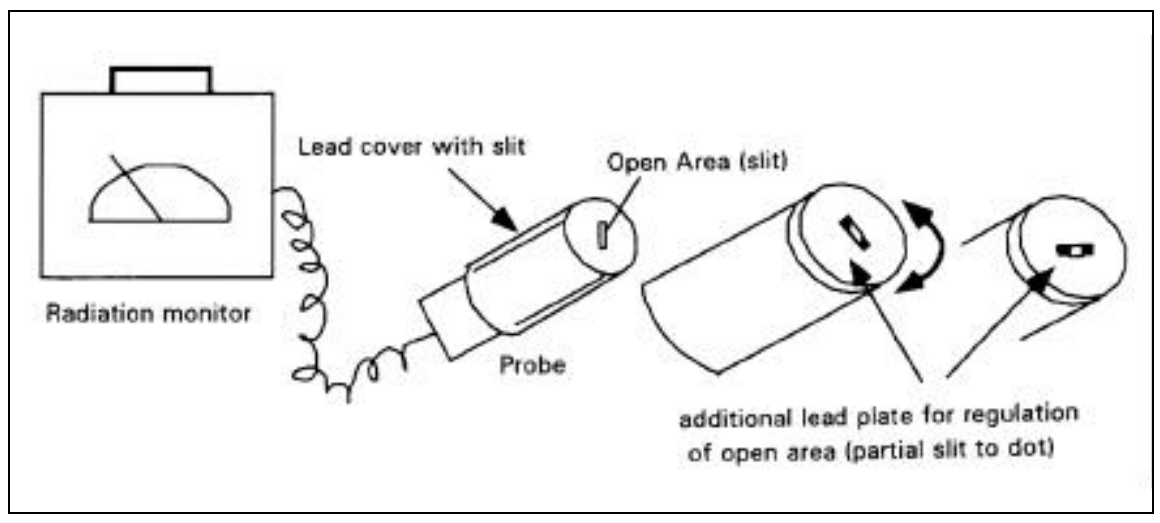

Figure 1. Modified radiation monitor for in vivo measurements of biodistribution kinetics. 